The Classical Review

http://journals.cambridge.org/CAR

Additional services for The Classical Review:

Email alerts: $\underline{\text { Click here }}$

Subscriptions: Click here

Commercial reprints: $\underline{\text { Click here }}$

Terms of use : $\underline{\text { Click here }}$

\title{
Third-Century Epigraphic Hands
}

Stephen Lambert

The Classical Review / Volume 55 / Issue 01 / March 2005, pp 322 - 324

DOI: 10.1093/clrevj/bni177, Published online: 25 April 2006

Link to this article: http://journals.cambridge.org/abstract_S0009840X04005001

How to cite this article:

Stephen Lambert (2005). Third-Century Epigraphic Hands. The Classical Review, 55, pp 322-324 doi:10.1093/clrevj/bni177

Request Permissions : $\underline{\text { Click here }}$ 
the 'anthropological approaches' never make it from the blurb of the book into its contents. Works that could have provided the concepts required in a study such as this (e.g. J. Hall, Ethnic Identity in Greek Antiquity [Cambridge, 1997]; A. Smith, The Ethnic Origins of Nations [Oxford, 1986]), let alone the concepts themselves, are deplorably absent. More importantly, H.'s main argument is fatally flawed. A (shorter) catalogue of votives existed long before the Romans appeared on the scene, i.e. in the Lindian archives and in the letters sent by the priests of Athana Gorgosthenes and Hieroboulos to the Rhodian Council and to the Lindian mastroi in the fourth century B.C. What we are asked to believe, moreover, is this: one of the compilers, Timachidas, had for some time been cultivating his own antiquarian interests (p. 61), until his father proposed the initiation of the very research project which aimed at documenting to the world Lindos' glorious past, and which was to be published (just one month after the proposal) on a stele that, once in place, would have impressed the visitor by the 'awe and intimacy' which characterized the special relationship claimed by the Lindians between them and the goddess Athana (pp. 292-3), but nonetheless a stele whose text, according to H. (p. 156), would have been extremely difficult for a visitor to read, if, indeed, any such found cause to 'come to the tiny village of Lindos' (p. 291). Ultimately, then, not only did Timachidas quite coincidentally produce what his 'fatherland' needed most urgently, but also the Lindians went to all that trouble for, and put their hopes in, a stone that was largely illegible.

In sum, because of this book's uneven quality, readers are generally advised to use it with great caution. The Chronicle still awaits proper treatment.

University of Copenhagen

VINCENT GABRIELSEN doi:10.1093/clrevj/bni176

\section{THIRD-CENTURY EPIGRAPHIC HANDS}

S. V. Tracy: Athens and Macedon. Attic Letter-Cutters of 300 to 229 B. C. (Hellenistic Culture and Society 38.) Pp. xxii +205 , ills. Berkeley, Los Angeles, and London: University of California Press, 2003. Cased, US\$75, £49.95. ISBN: 0-520-23333-6.

Tracy's work on cutters is one of the most important recent developments in epigraphy. Identifying the cutter dates an inscription to within a generation and facilitates the joining of fragments by narrowing the pool of candidates typically from hundreds or thousands to less than fifty: dating and joins - two of the epigraphist's central tasks. T. is not the first scholar to identify an epigraphical hand, but he is the first to have pursued the study on a systematic basis. Over the years he has made innumerable joins (and disjoins) and redatings, and every Attic epigraphist is deeply in his debt - one might say every serious historian occupied with Athens, for inscriptions are the most important source for Athenian history in the longue durée. The present book fills the gap between his Attic Letter-Cutters of 229 to 86 (Berkeley, 1990) and Athenian Democracy in Transition, Attic Letter-Cutters of 340 to 290 (Berkeley, 1995) (ADT). If the harvest is less abundant, it is because he has already identified the two most prolific cutters of the period, those of Agora I 3238 and of $I G$ $\mathrm{II}^{2} 788$, in an earlier study. T. now adds 10-20 new items to their dossiers, presents six (rather unprolific) cutters for the first time, identifies three smaller groups of two or

The Classical Review vol. 55 no. 1 (C) The Classical Association 2005; all rights reserved 
three inscriptions cut by the same hand, and supplies addenda to three of the cutters in $A D T$.

Presentation follows T.'s well-established pattern: for each cutter meticulous description of the lettering, illustrated by photographs (which are outstanding in this volume), a list of the inscriptions allocated, with helpful bibliography and longer notes on new readings, joins etc., including some first editions of small fragments from the Agora.

A very welcome development is a broadening of the analysis to include matters such as use of stoichedon (or not-in this period the stoichedon style was progressively abandoned) and syllabification at line-ends, though a systematic study of how far specific stoichedon grids are characteristic of individual cutters remains a desideratum (for an example of the importance of this issue in relation to [dis]joins, see ZPE 136 [2001], 65-70). More work also needs to be done on how far these features were the responsibility of the cutter, as T. tends to assume, or the decree proposer, secretary, or, conceivably, workshop foreman. It is implausible to attribute politically charged aspects of layout, e.g. highlighting the name of the proposer (pp. 144-7), solely to the cutter, and orthographical variants and errors (attributed to the cutter e.g. on p. 125) may be due to the text from which he was working.

As usual, T. makes significant contributions of historical fact. Shifting the archon Aristion from $238 / 7$ to $c .290$ brings nearer the important objective of establishing a full chronological framework for third century Athens. $I G \mathrm{II}^{2} 513$ is convincingly dissociated from the orator Lykourgos. There is significant progress on inscriptions relating to Lemnos $\left(I G \mathrm{II}^{2} 550,1222,735\right) . I G \mathrm{II}^{2} 928$ is redated from the second century to $c$. 245 (foreshadowed in T.'s earlier work, but missed by me, ZPE 142 [2003], 84), taking with it its honorand, Penteteris, priestess of Athena Polias, the sculptors Kaikosthenes and Dies, and nine dedications and statue bases. There are thoughtful remarks on neglected but important topics (e.g. pp. 54-5 on privately erected decrees). T.'s more extensive forays outside his specialist field, however, are less persuasive. The operation of the Assembly and Council in Hellenistic Athens shows that the institutions normal in Greek cities were maintained. Pace T. (pp. 9-14), it is not indicative of whether the constitution was 'democratic' or 'oligarchic'. That is a matter of whether power was exercised by the many or the few. In 321 citizenship was restricted to those with a certain level of property, the key criterion of oligarchy. There is little or no direct evidence as to franchise adjustments in 307 (though there was rhetoric about restoration of democracy) or on subsequent regime changes, and analysis of the distribution of power must proceed by other means, primarily statistical analysis of prosopographical data, which has yet to be systematically attempted for Hellenistic Athens (for a snapshot of the late second century see ZPE 142 [2003], 85-6).

Is T.'s method convincing? In that it is reasonably conceived and carefully executed, that (importantly) he sets out clear and verifiable criteria for each cutter, and that there has as yet been no persuasive attempt to undermine it, yes. Moreover, the number of certain joins he has made, while it does not strictly prove the method, suggests that it is along the right lines. If one hesitates, it is because he is operating practically in a field of his own (Michael Walbank has proposed many joins, a number of them convincing, but his claims to identify hands have been justly criticized by T. as methodologically untransparent). This means that we must take T.'s conclusions to an extent on trust until others with his skill and patience follow his lead into this demanding field. (Conventional editing of texts does not automatically equip one to make specific 
judgements on hands, as the focus of attention is different.) The prospects are not good. As T. himself states:

complete study of any given cutter requires literally years of work ... these factors, namely the need to devote oneself full-time to the study . . . militate against anyone undertaking it, even the most tenacious. In the present academic climate, it is certainly not a line of enquiry that one can recommend to young scholars.

One might apply the same remarks to epigraphy in general. Neither in Britain nor in the USA are there satisfactory arrangements for the accommodation of this fundamentally important but highly laborious and skill-rich research field within the university system, and it is increasingly falling to scholars working outside it to carry the flame.

Terrington, Yorkshire

STEPHEN LAMBERT

doi:10.1093/clrevj/bni177

\section{EPITAPHS}

G. J. Oliver (ed.): The Epigraphy of Death. Studies in the History and Society of Greece and Rome. Pp. xiv + 225, ills. Liverpool: Liverpool University Press, 2000. Paper, £16.95. ISBN: 0-85323-915-0.

This volume, the result of a conference on Greek and Roman funerary inscriptions organized by G. J. Oliver and E. G. Clark at the University of Liverpool in 1995, brings together seven essays on various uses of the inscriptional evidence of gravestones to illuminate the social history of the classical world. A thoughtful introductory chapter by $\mathrm{O}$. sets the several contributions into the broader context of the epigraphic and funerary cultures of Athens and Rome, and emphasizes the importance of regarding epitaphs as integral elements within a network of ritual, social, and especially archaeological contexts. There follow five case studies, arranged chronologically, which to a greater or lesser extent illustrate the central proposition, proceeding from developments in classical Athenian funerary sculpture (K. Stears) and tomb monuments (G. Oliver), to Milesian immigration into late Hellenistic and Roman Athens (T. Vestergaard, with a note on the silting up of Miletus' harbors by A. Greaves), to the commemoration of infants in Rome (M. King) and the sculpted tombstones of Roman auxiliary soldiers at Mainz (V. Hope). A final chapter considers the importance of inscriptions (authentic and fake) to collectors of ash urns during the seventeenth and eighteenth centuries (G. Davies). Some thirty-five figures and black and white photographs, an index locorum, and a general index complete the volume.

With the exception of the final chapter by Davies, 'The Inscriptions on the Ash Chests of the Ince Blundell Hall Collection: Ancient and Modern' (a primer on distinguishing the spurious from the authentic and a cautionary tale: fewer than half of some fifty in the collection are certainly genuine), all of the essays are broadly concerned with ways in which different groups in Athenian and Roman society represented themselves or can be identified through the medium of the inscribed funerary monument. Statistical arguments - inevitable with discussions involving analysis of epitaphs in quantity - are there to be found, particularly in the chapters by Vestergaard and King, but the authors are generally less concerned with demographic

The Classical Review vol. 55 no. 1 (C) The Classical Association 2005; all rights reserved 